\title{
The Investigation of Indium-Free Amorphous Zn-Al-Sn-O Thin Film Transistor Prepared by Magnetron Sputtering
}

\author{
Mingyu Zhang ${ }^{1}$, Kuankuan Lu ${ }^{1}$, Zhuohui Xu ${ }^{2}$, Honglong Ning ${ }^{1, *(\mathbb{D},}$, Xiaochen Zhang ${ }^{1}$, Junlong Chen ${ }^{1}$, \\ Zhao Yang ${ }^{1,3}$, Xuan Zeng ${ }^{1}$, Rihui Yao ${ }^{1, * \mathbb{C}}$ and Junbiao Peng ${ }^{1}$ \\ 1 State Key Laboratory of Luminescent Materials and Devices, Institute of Polymer Optoelectronic Materials \\ and Devices, South China University of Technology, Guangzhou 510640, China; \\ 201866320381@mail.scut.edu.cn (M.Z.); mskk-lu@mail.scut.edu.cn (K.L.); zhangxc_scut@foxmail.com (X.Z.); \\ msjlchen@gmail.com (J.C.); yangzhao@china-fenghua.com (Z.Y.); zengxuanbbj@foxmail.com (X.Z.); \\ psjbpeng@scut.edu.cn (J.P.) \\ 2 Guangxi Key Lab of Agricultural Resources Chemistry and Biotechnology, Yulin Normal University, \\ Yulin 537000, China; xzh21@ylu.edu.cn \\ 3 State Key Laboratory of Advanced Materials and Electronic Components, Fenghua Electronic Industrial Park, \\ No. 18 Fenghua Road, Zhaoqing 526020, China \\ * Correspondence: ninghl@scut.edu.cn (H.N.); yaorihui@scut.edu.cn (R.Y.)
}

check for

updates

Citation: Zhang, M.; Lu, K.; Xu, Z.; Ning, H.; Zhang, X.; Chen, J.; Yang, Z.; Zeng, X.; Yao, R.; Peng, J. The Investigation of Indium-Free Amorphous Zn-Al-Sn-O Thin Film Transistor Prepared by Magnetron Sputtering. Coatings 2021, 11, 585. https://doi.org/10.3390/ coatings11050585

Academic Editor: You Seung Rim

Received: 16 April 2021

Accepted: 13 May 2021

Published: 17 May 2021

Publisher's Note: MDPI stays neutral with regard to jurisdictional claims in published maps and institutional affiliations.

Copyright: (c) 2021 by the authors. Licensee MDPI, Basel, Switzerland. This article is an open access article distributed under the terms and conditions of the Creative Commons Attribution (CC BY) license (https:// creativecommons.org/licenses/by/ $4.0 /)$

\begin{abstract}
The indium-free amorphous oxide semiconductor thin film transistor (AOS-TFT) with aluminum (Al) electrodes shows broad application prospects in new-generation display technologies, such as ultra-high definition large-screen display, OLED display and 3D display. In this work, the thin film transistor (TFT) with a zinc-aluminum-tin-oxide (ZATO) semiconductor as the active layer and an $\mathrm{Al}$ electrodes as the source and drain (S/D) was investigated. The optical, electrical and semiconductive properties of the ZATO films were evaluated by atomic force microscopy (AFM), ultraviolet-visible spectrophotometry and microwave photoconductivity decay ( $\mu$-PCD), respectively. The result shows that the film is smooth and transparent and has low localized states and defects at a moderate oxygen concentration $(\sim 5 \%)$ and a low sputtering gas pressure ( $\sim 3$ mTorr $)$. After the analysis of the transfer and output characteristics, it can be concluded that the device exhibits an optimal performance at the $623 \mathrm{~K}$ annealing temperature with an $\mathrm{I}_{\text {on }} / \mathrm{I}_{\text {off }}$ ratio of $5.5 \times 10^{7}$, an SS value of $0.15 \mathrm{~V} /$ decade and a saturation mobility $\left(\mu_{\mathrm{sat}}\right)$ of $3.73 \mathrm{~cm}^{2} \cdot \mathrm{V}^{-1} \cdot \mathrm{s}^{-1}$. The ZATO TFT at the $623 \mathrm{~K}$ annealing has a $-8.01 \mathrm{~V}$ negative shift under the $-20 \mathrm{~V}$ NBS and a $2.66 \mathrm{~V}$ positive shift under the $20 \mathrm{~V}$ PBS.
\end{abstract}

Keywords: indium-free; ZATO; magnetron sputtering; microwave photoconductivity decay; thin film transistors

\section{Introduction}

The technology of display plays an important role in the development of the electronic information industry. Nowadays, mainstream display technologies include AMOLED, $\mu L E D$ and AMLCD [1]. As a key part of these display technologies, the research of high-performance and environmentally friendly thin film transistors (TFTs) is of great significance. The current TFTs mainly include amorphous silicon (a-Si) TFTs, low temperature polycrystalline silicon (LTPS) TFTs, amorphous oxide semiconductor (AOS) TFTs, organic semiconductor TFTs (OTFTs), etc. However, a-Si TFTs [2] have low open current and cost a lot, the uniformity of LTPS TFTs [3,4] is poor and the OTFTs [5] have poor stability. AOS TFTs possess a broad development prospect in this field due to their excellent stability [6], good uniformity, high mobility [7] and low-cost, which has attracted the attention of scholars worldwide.

The main materials used as AOS TFTs include zinc oxide $(\mathrm{ZnO})$, indium oxide $\left(\mathrm{In}_{2} \mathrm{O}_{3}\right)$ and tin oxide $\left(\mathrm{SnO}_{2}\right)$. However, $\mathrm{In}_{2} \mathrm{O}_{3}$ is toxic and expensive, and the performance of $\mathrm{SnO}_{2}$ is not good enough. Although indium zinc oxide (IZO) and indium gallium zinc 
oxide (IGZO) have good performances, both contain indium, a rather expensive and toxic precious metal element which is harmful to the environment. To overcome these issues, it is necessary to develop indium-free $\mathrm{ZnO}$ semiconductive materials. In previous studies [8], it was proved that the ZATO films can significantly improve the conductivity and transparency of the $\mathrm{ZnO}$ films [9,10], so it shows great application potential. The main methods of thin film preparation include vacuum evaporation [11], electron beam deposition [12], chemical vapor deposition [13] and magnetron sputtering [14]. Among all of these, the magnetron sputtering has numerous advantages, such as high deposition rates, low substrate temperatures and good adhesion of the films on the substrate [15], which exhibits a lot of potential in depositing and growing the thin films [16]. Before this work, Jiang et al. studied the ZATO TFTs and found that they exhibited acceptable performances at an optimal Al content (0.5) [17]. Based on this, we investigated the performance of the ZATO films at different pressures and oxygen/argon ratios and the ZATO TFTs at different annealing temperatures at a $0.5 \mathrm{Al}$ content to obtain the best condition of the device. Therefore, in this paper, we fabricated the ZATO TFTs by radio frequency (RF) magnetron sputtering to investigate their properties.

Under the guidance of the Taguchi orthogonal design method [18], the properties of the ZATO films were studied. After the comprehensive analysis and comparison, the best condition for the film growth was obtained, and the TFTs with the ZATO films as the active layer and the $\mathrm{Al}$ electrodes as the S/D were prepared on this basis.

\section{Materials and Methods}

ZATO TFT was prepared on the alkali-free glass substrate with $100 \mathrm{~nm}$-thick $\mathrm{Al}-$ $\mathrm{Nd}$ alloy gate electrode deposited by direct current (DC) magnetron sputtering, which is covered by $200 \mathrm{~nm}$-thick anodized $\mathrm{AlO}_{x}$ : $\mathrm{Nd}$ insulator using anodic oxidation [19], as shown in Figure 1. Figure 1a is practical image, and Figure $1 \mathrm{~b}$ is schematic map of cross-section image of ZATO TFT. The ZATO target (Zn:Al:Sn = 4:0.5:7 at.\%) was used to deposit $30 \mathrm{~nm}$-thick ZATO active layers patterned through a stencil shadow mask [20]. In order to obtain the optimal growth condition of the films, ZATO target was sputtered at a power of $80 \mathrm{~W}$ with different pressure and oxygen/argon flow ratios. After that, the active layers were annealed at $523 \mathrm{~K}, 573 \mathrm{~K}, 623 \mathrm{~K}$ and $673 \mathrm{~K}$ in air atmosphere for $1 \mathrm{~h}$. Ultimately, the $200 \mathrm{~nm}$-thick $\mathrm{Al}$ source and drain electrodes patterned through a stencil shadow mask were prepared at a power of $100 \mathrm{~W}$ by radio frequency $(\mathrm{RF})$ magnetron sputtering.
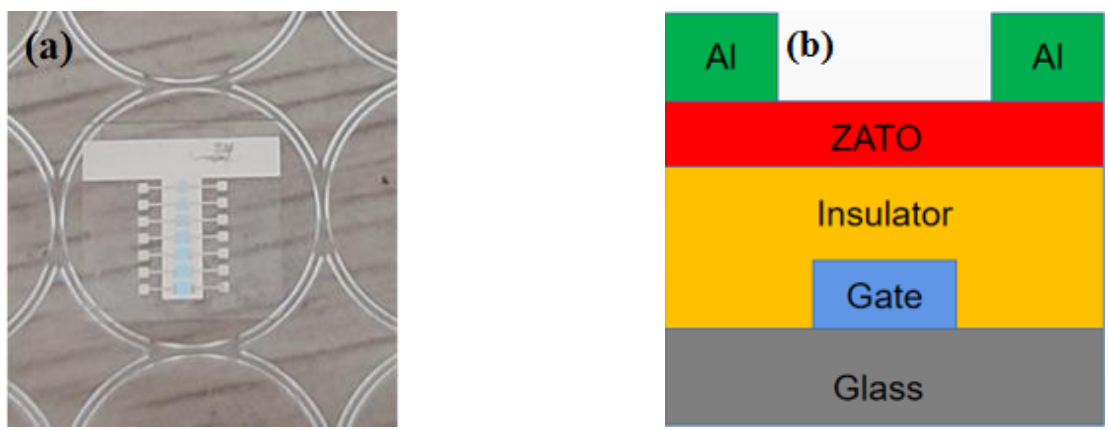

Figure 1. Image of ZATO TFTs device: (a) Practical and (b) schematic map of cross-section.

Experimental schemes for ZATO films in this work were determined by Taguchi orthogonal design. Eighteen schemes were obtained with sputtering pressure of 3 levels ( 3 mTorr, 5 mTorr and 8 mTorr); oxygen/argon ratio of 3 levels ( $(0 \%, 5 \%$ and $10 \%$ ) and annealing temperature of 6 levels. The five most represented groups were selected for research, as shown in Table 1. 
Table 1. Different conditions for ZATO thin films fabrication.

\begin{tabular}{ccc}
\hline Pressure (mTorr) & Oxygen/Argon Ratio (\%) & Annealing Temperature (K) \\
\hline 3 & 5 & 298 \\
5 & 5 & 298 \\
3 & 0 & 298 \\
3 & 5 & 523 \\
3 & 5 & 623 \\
\hline
\end{tabular}

Atomic force microscopy (AFM) (BY3000, Being Nano-Instruments Ltd., Guangzhou, China) was used to characterize the morphology of $50 \mathrm{~nm}$ ZATO films with different pressures, different oxygen/argon ratios and different annealing temperatures prepared on glass substrate. The absorption and transmittance of the films were measured with ultraviolet-visible spectrophotometer (Shimadzu UV-2600, Shimadzu Corporation, Shimadzu, Japan). The semiconductor properties of the films were tested by microwave photoconductivity decay ( $\mu$-PCD) (LTA-1620SP, KOBELCO, Kobe, Japan). The semiconductor parameter analyzer (Aglient 4155C, Dongguan nuozhan electronic instrument Co. Ltd., Dongguan, China) was used to investigate the electrical characteristics of TFTs, and the carrier mobility $\left(\mu_{\text {sat }}\right)$, threshold voltage $\left(\mathrm{V}_{\text {th }}\right)$, switching state current ratio $\left(\mathrm{I}_{\text {on }} / \mathrm{I}_{\text {off }}\right)$ and subthreshold swing (SS) are extracted from the measured transfer output characteristic curves to characterize the properties of TFTs.

\section{Results and Discussion}

\subsection{Film Morphology}

Figure 2 shows the surface images of the ZATO films prepared under different conditions by using AFM, with a scanning range of $1.5 \mu \mathrm{m} \times 1.5 \mu \mathrm{m}$. The root mean square $\left(\mathrm{S}_{\mathrm{q}}\right)$ of these films is as low as $0.506 \mathrm{~nm}$, and all films are smooth and flat, which can ensure the normal operation of the TFTs. From Figure 2a,b, it can be seen that the roughness of the ZATO films is rarely reduced with the increasing pressure. Besides, compared with Figure $2 \mathrm{a}, \mathrm{c}$, it is found that increasing the oxygen content is beneficial to improve the surface morphology of the ZATO films. However, Figure $2 \mathrm{a}, \mathrm{d}$,e indicate that the evaporation intensifies with the increase of annealing temperatures, and the film particles are fused and result in the growth of film grains, which finally causes greater roughness of the ZATO films [21,22].

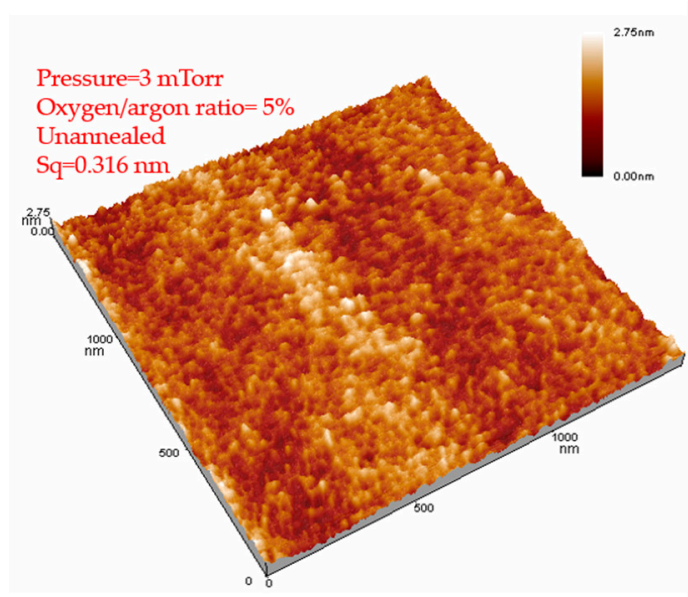

(a)

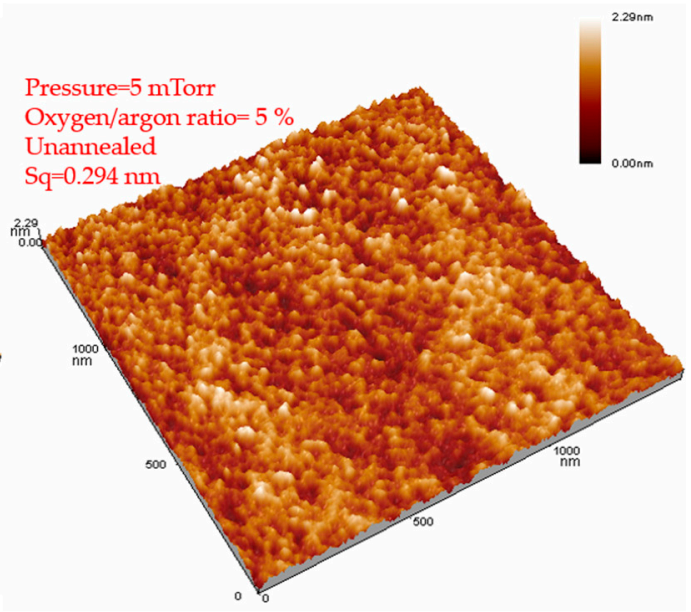

(b)

Figure 2. Cont. 


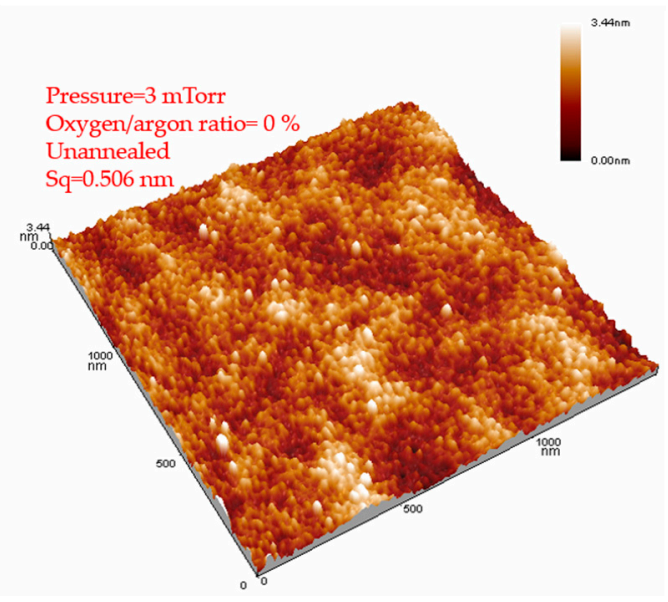

(c)

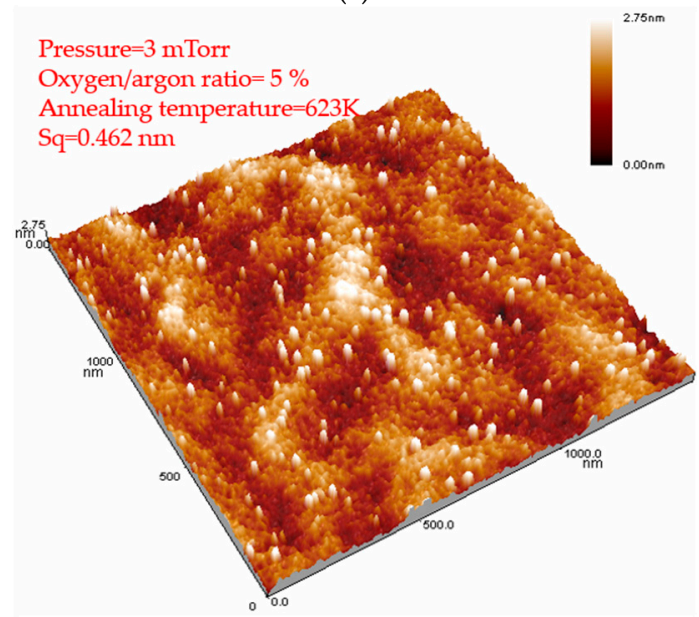

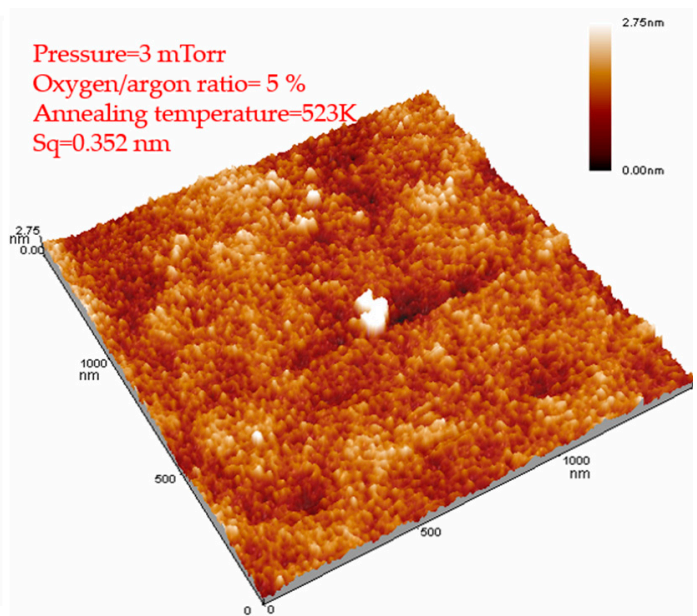

(d)

(e)

Figure 2. (a-e) AFM images of ZATO films at different pressure, oxygen contents and annealing temperatures.

\subsection{Optical Characterization}

Figure 3 illustrates the optical transmittance spectra $(300-800 \mathrm{~nm})$ and $(\alpha h v)^{2}$ versus $h v$ plots of the ZATO films at different pressures, different oxygen/argon ratios and different annealing temperatures. In order to eliminate the influence of the substrate, the deposited ZATO films were measured and analyzed with an uncoated glass substrate as calibration when testing the transmittance of the ZATO films.

Figure $3 \mathrm{a}, \mathrm{b}$ are the transmission spectra for the ZATO thin films at different pressures and different oxygen/argon ratios. From Figure $3 a, b$, they show that the transmittance of the films in the visible light region is above $70 \%$. With the increasing pressure, oxygen vacancy defects decrease, and the loss of light reduces, which leads to the enlargement of transmittance [23-25]. Besides, as the oxygen content continues to increase, the transmittance decreases. The transmittance of the ZATO films gradually decreases with the decrease of the spectral wavelength, which is attributed to the increase of light absorption in the near-ultraviolet band. Figure $3 \mathrm{c}$ is the transmission spectra for the ZATO thin films at $3 \mathrm{mTorr}$ and $5 \%$ oxygen content with different annealing temperatures. From Figure $3 \mathrm{c}$, it can be found that the optical properties of the ZATO films are greatly improved after the $523 \mathrm{~K}$ and $623 \mathrm{~K}$ annealing. All the ZATO films have high average transmittance values (up to $90 \%$ ) in the visible region, which suggests that the ZATO films have the potential ability for fabricating transparent TFTs. As the annealing temperature increases, the residual stress of the films is released, and the defects of the thin film are recovered, so the absorption and visible light scattering of the thin film are decreased. As a direct band gap semiconductor, the value of the optical band gap $\left(E_{g}\right)$ of the ZATO films is fitted from the extrapolation 
of the linear line portion of the plot of $(\alpha h v)^{2}$ versus (hv), as shown in Figure 3a-c. The following equation is satisfied between the absorption coefficient $(\alpha)$ and the incident photon energy ( $h v)$ as Formula (1) [26]:

$$
(\alpha h v)^{2}=A\left(h v-E_{g}\right)
$$

In this formula, $h$ is Planck's constant, $v$ is the frequency of light, $A$ is the constant and $E_{g}$ is the optical band gap. The linear absorption edge was obtained from the $(\alpha h v)^{2}$ versus $h v$ diagram of the absorption spectrum, and the band gap can be obtained at the intercept of the energy axis by extending the linear absorption edge in reverse.
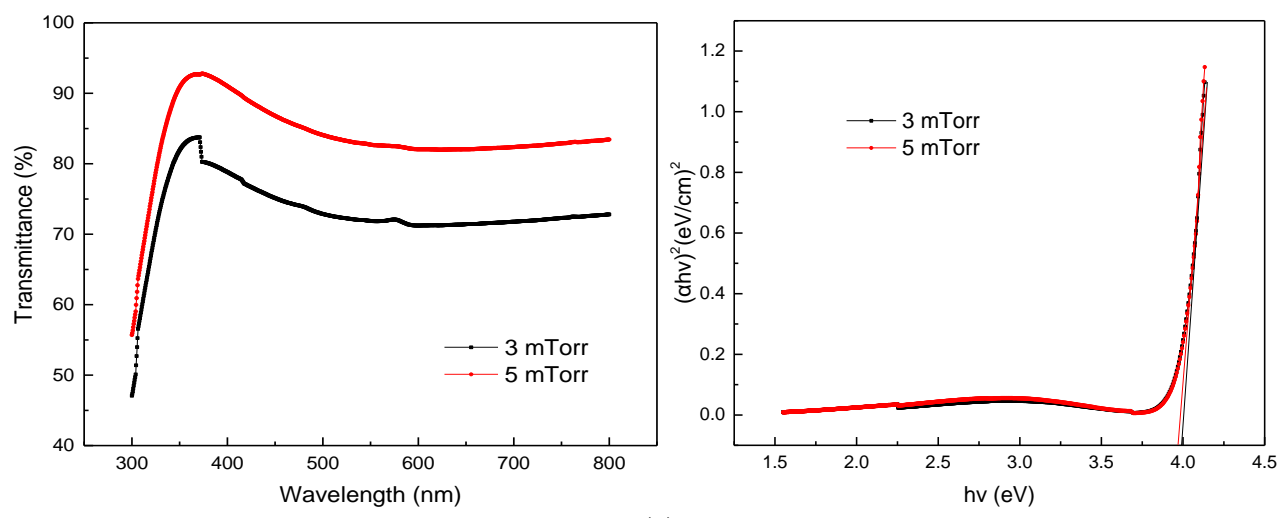

(a)
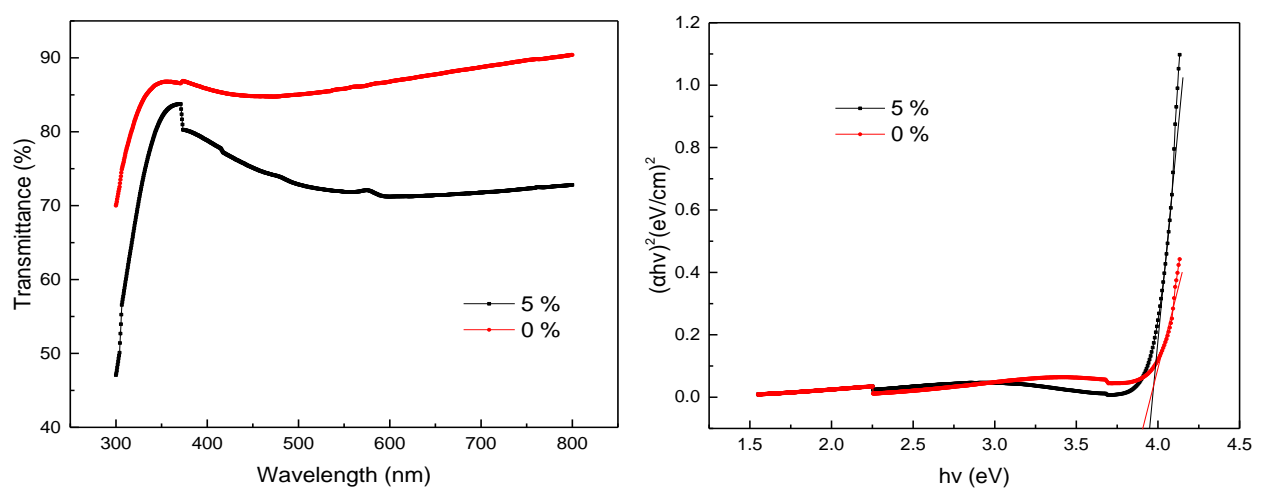

(b)
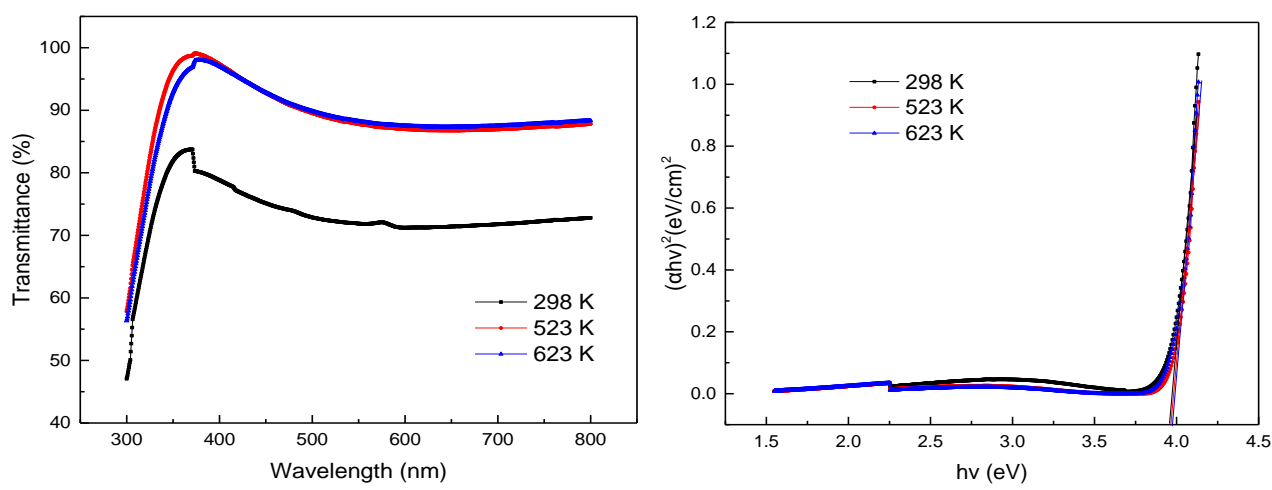

(c)

Figure 3. Optical transmittance spectra and $(\alpha h v)^{2}$ versus $h v$ plots of ZATO films: (a) Different gas pressure (at $5 \%$ oxygen content and unannealed), (b) different oxygen/argon ratios (at 3 mTorr and unannealed) and (c) different annealing temperatures (at 3 mTorr and 5\% oxygen/argon ratio). 
Figure 4 is the relationship between the optical band gaps and samples under different conditions. From Figure 4, it can be seen that the band gap widens with the increasing of the oxygen content. The possible reason is that, with an increasing of the oxygen content, the defects in the films reduce, and the carrier concentration of the ZATO films increases; the rise in the Fermi level in the semiconductor causes the band gap to increase, which may be explained by the Burstein-Moss effect $[27,28]$. When the pressure is low, there are lots of oxygen vacancies in the films, and the carrier concentration is high; for this reason, the band gap of the ZATO films at 3 mTorr and $5 \%$ oxygen content is larger than that at $5 \mathrm{~m}$ Torr and $5 \%$ oxygen content. Besides, the improvement of the optical band gap after the annealing identifies that the annealing is helpful to increase the carrier concentration of the thin films.

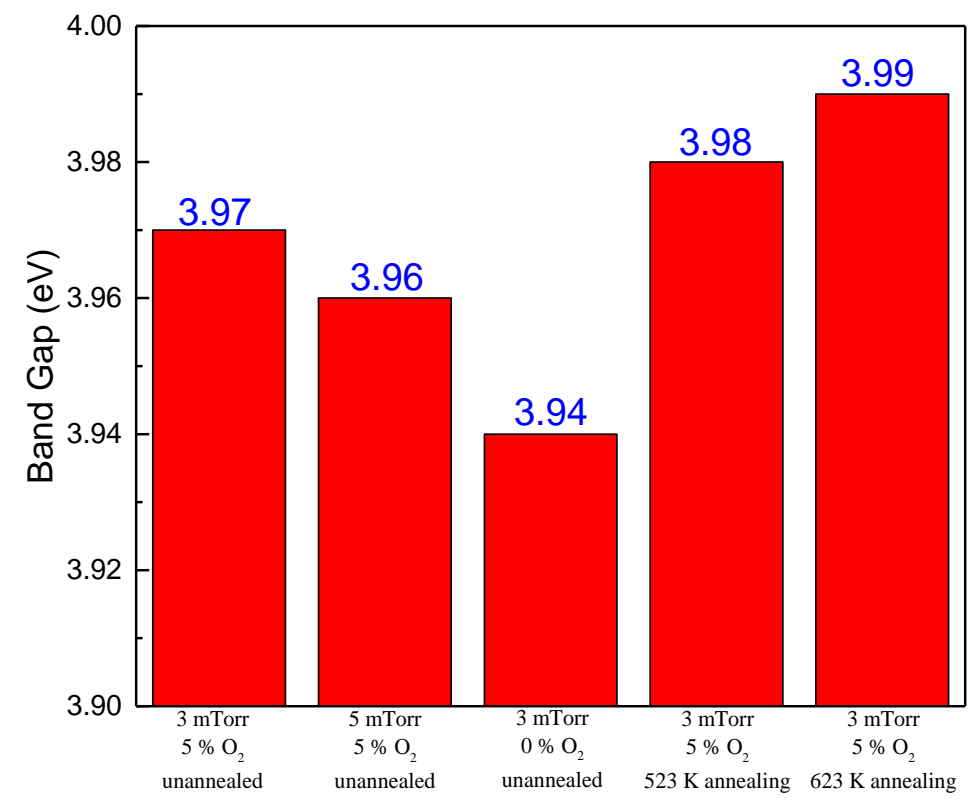

Figure 4. Band gap changes under different conditions.

\subsection{Characterization of Semiconductor Properties of Thin Films}

Figure 5a-e are the images of the microwave photoconductive decay ( $\mu$-PCD) mapping scan of the ZATO films at different pressures, oxygen contents and annealing temperatures. From Figure 5, it shows that the homogeneity and carrier mobility of the ZATO films after the annealing are greatly improved. Figure 6 shows the photoelectric response curves of the ZATO films under different conditions by the $\mu$-PCD method. From Figure 6 , the mean peak value and $\mathrm{D}$ value can be extracted from the curves, and the mean peak and $\mathrm{D}$ value change under different conditions that are obtained. Figure 7 is the relationship between the mean peak value, $\mathrm{D}$ value and samples under different conditions. From Figure 7, it can be found that the peak value of the annealing sample is higher than that of no annealing sample, and the $\mathrm{D}$ value has a slight decrease, which indicates that the annealing process is beneficial to the suppression of the defects in the mid-gap states. When gas pressure increases, the mean peak value and D value of the ZATO films become higher. As the oxygen/argon ratios increase from $0 \%$ to $5 \%$, the mean peak value and $\mathrm{D}$ value of the ZATO films are also becoming higher, perhaps the density of mid-gap defects and shallow localized defects decrease greatly, and it can help the TFT devices to improve their performance and stability $[29,30]$. The peak reflectivity signal can reflect the density of the conduction band tail state; the high peak value indicates that the defect density of the gap state is low, which is closely related to the performance of the transistors. The shallow localized states are evaluated by the $\mathrm{D}$ values; the higher $\mathrm{D}$ values indicate the lower defect density of the captured or released shallow localized states, which is related to the device 
stability [31-35]. In addition, the optimization of the ZATO film is as follows: 3 mTorr pressure and $5 \%$ oxygen content at the $523 \mathrm{~K}$ annealing.
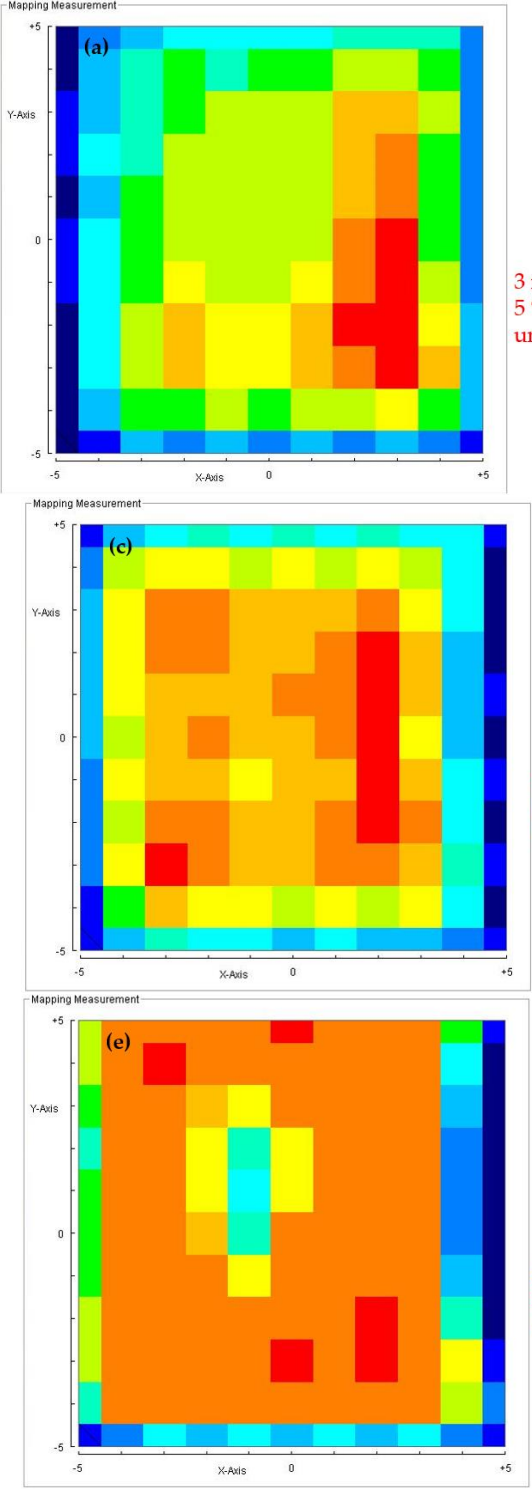

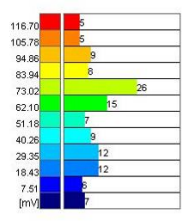

3 mTorr

$5 \%$ oxygen content unannealed

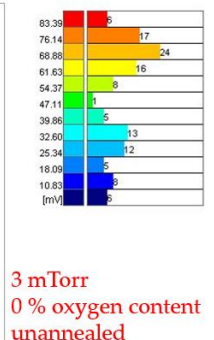

unannealed

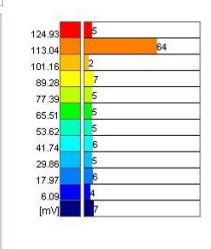

3 mTorr

$5 \%$ oxygen content

$623 \mathrm{~K}$ annealing
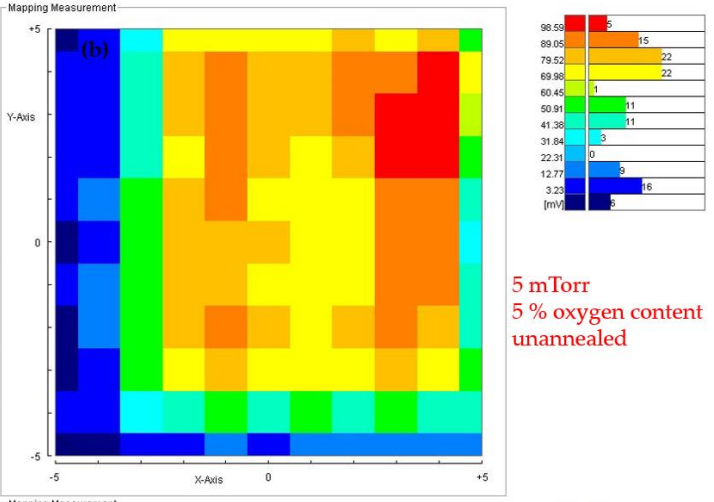

5 mTorr

$5 \%$ oxygen content

unannealed

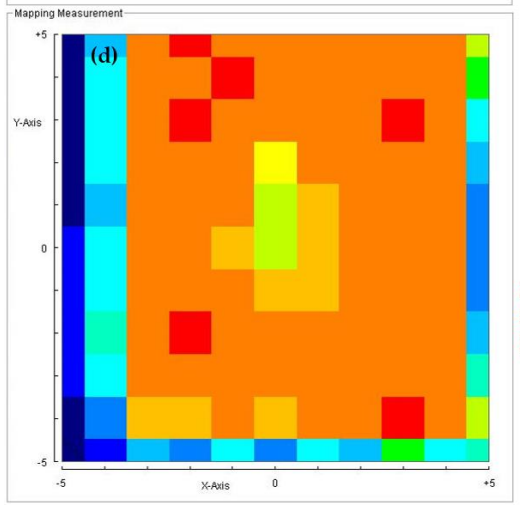

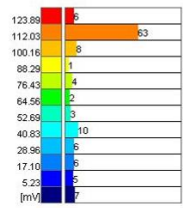

3 mTorr

$5 \%$ oxygen content

$523 \mathrm{~K}$ annealing

Figure 5. Images of $\mu$-PCD mapping scan of ZATO films at different pressure, oxygen contents and annealing temperatures.
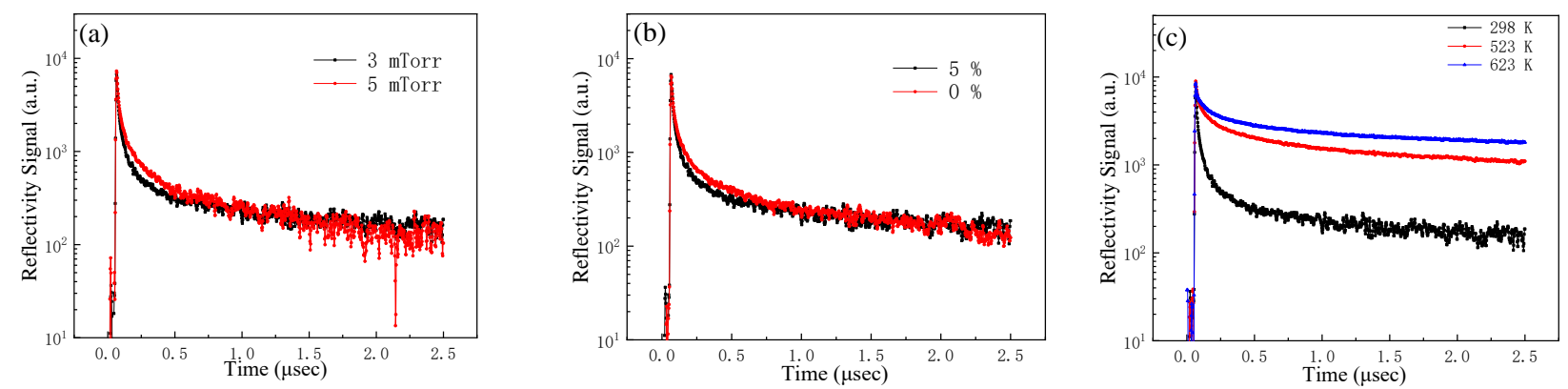

Figure 6. The photoelectric response curves of the ZATO films: (a) at different pressure (at 5\% oxygen content and unannealed), (b) at different oxygen/argon ratios (at 3 mTorr and unannealed) and (c) at different annealing temperatures (at 3 mTorr and 5\% oxygen/argon ratio). 


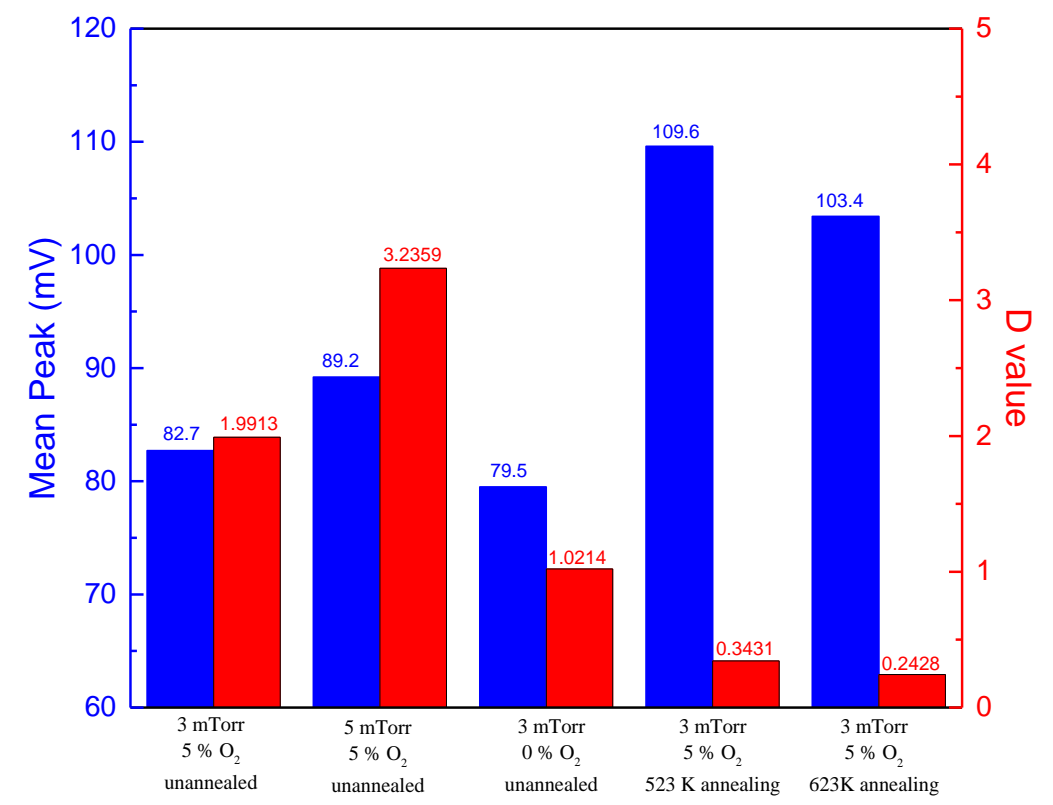

Figure 7. Peak value and D value changes under different conditions.

\subsection{Characterization of ZATO TFTs with Different Annealing Temperatures}

The $30 \mathrm{~nm}$ ZATO film was prepared as the active layer at $3 \mathrm{mTorr}$ and 5\% oxygen content by radio frequency (RF) magnetron sputtering. The $200 \mathrm{~nm}$ Al electrodes [36,37] were prepared on the active layer as the S/D after the films were annealed at $523 \mathrm{~K}$, $573 \mathrm{~K}, 623 \mathrm{~K}$ and $673 \mathrm{~K}$. The TFT devices with the ZATO films as the active layer were successfully prepared in this way. The electrical characteristics of the TFTs at different annealing temperatures were measured using a semiconductor analyzer (Aglient 4155C, Dongguan nuozhan electronic instrument Co. Ltd., Dongguan, China) in dark and air environments, and the output and transfer characteristics for the $523 \mathrm{~K}$ annealing, $573 \mathrm{~K}$ annealing, $623 \mathrm{~K}$ annealing and $673 \mathrm{~K}$ annealing devices are shown in Figure 8a-d. The output curves of the ZATO TFTs were obtained with $V_{G}=0-20 \mathrm{~V}$ in steps of $1 \mathrm{~V}$, while the transfer characteristics were measured with $V_{D}=20 \mathrm{~V}$.
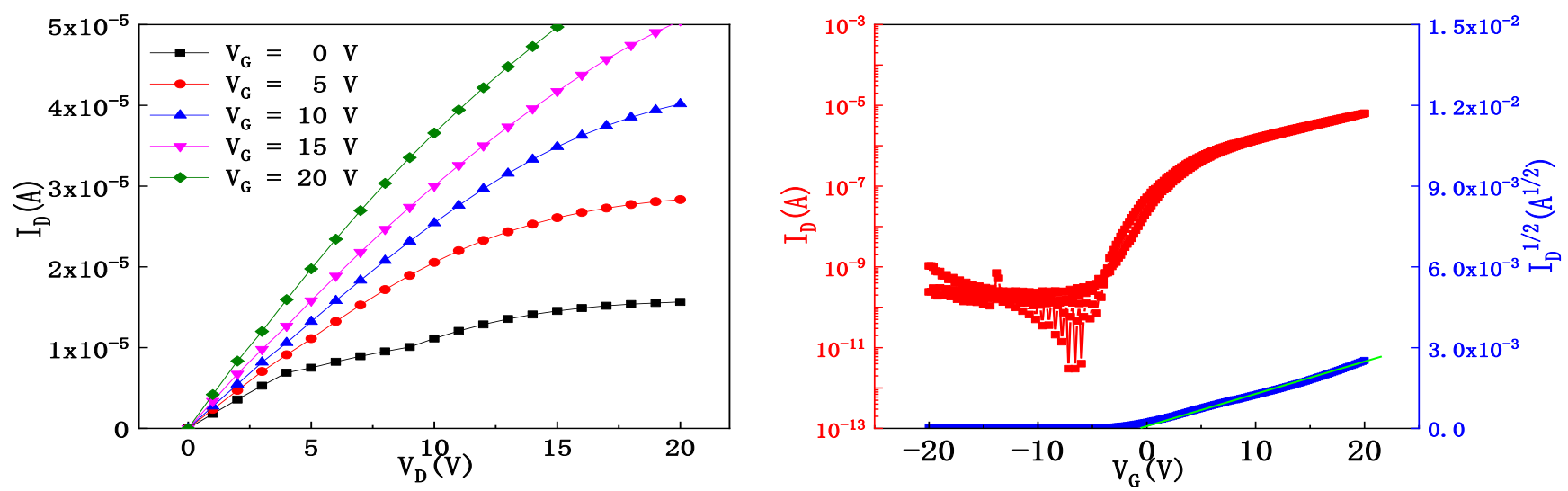

(a)

Figure 8. Cont. 

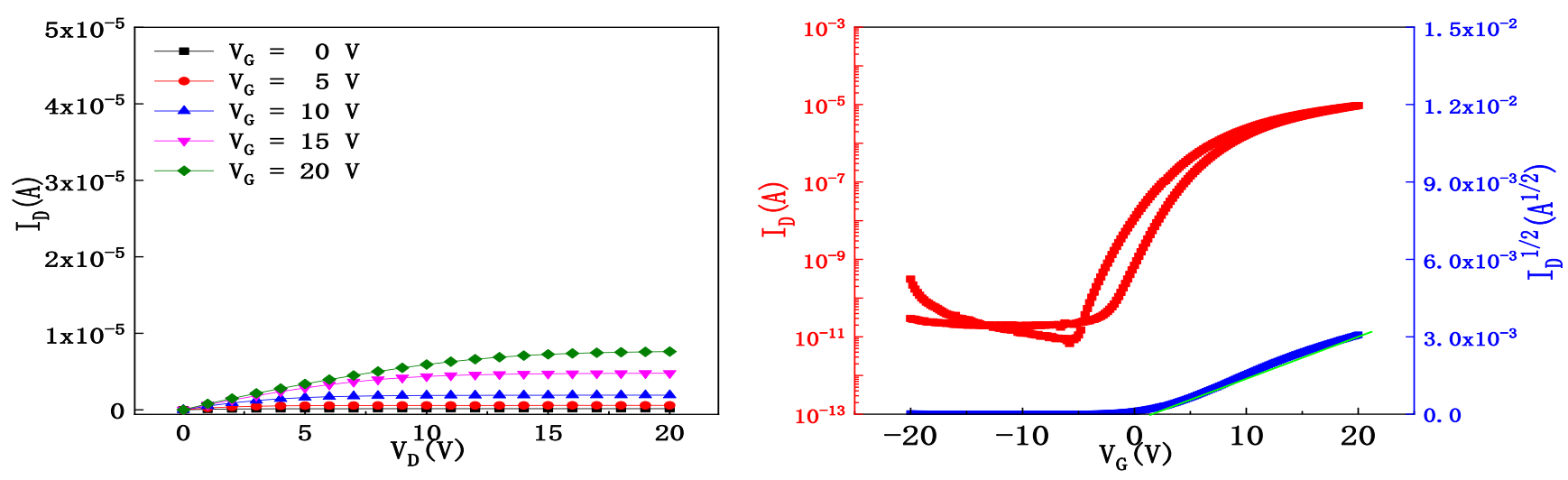

(b)
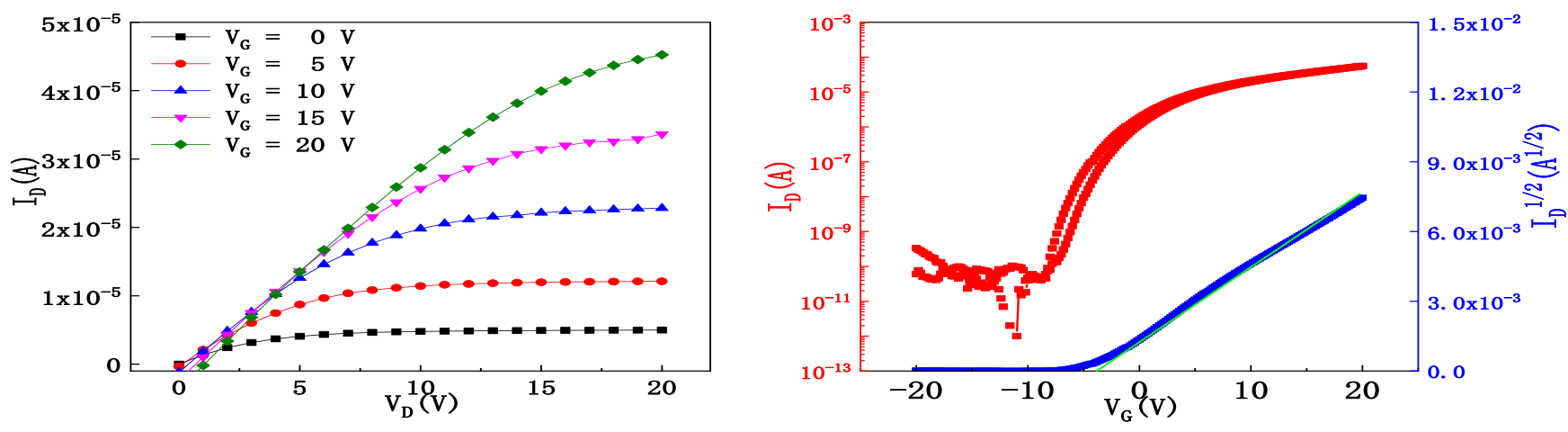

(c)
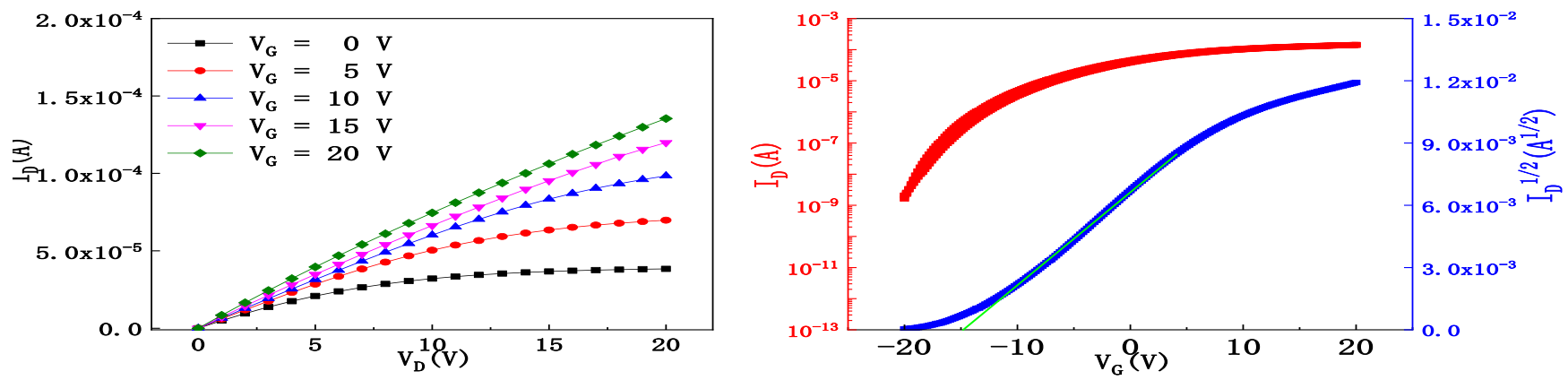

(d)

Figure 8. The output and transfer curves of TFT devices at: (a) $523 \mathrm{~K}$, (b) $573 \mathrm{~K}$, (c) $623 \mathrm{~K}$ and (d) $673 \mathrm{~K}$.

Figure 9 shows the main device performances of the TFTs at different annealing temperatures. From Figure 9, it can be analyzed that the on-state current increases gradually, while the off-state current decreases gradually with increasing annealing temperatures, which causes the $\mathrm{I}_{\mathrm{on}} / \mathrm{I}_{\text {off }}$ ratio increases in the meanwhile, and it reaches the maximum value of $5.55 \times 10^{7}$ after the $623 \mathrm{~K}$ annealing. 

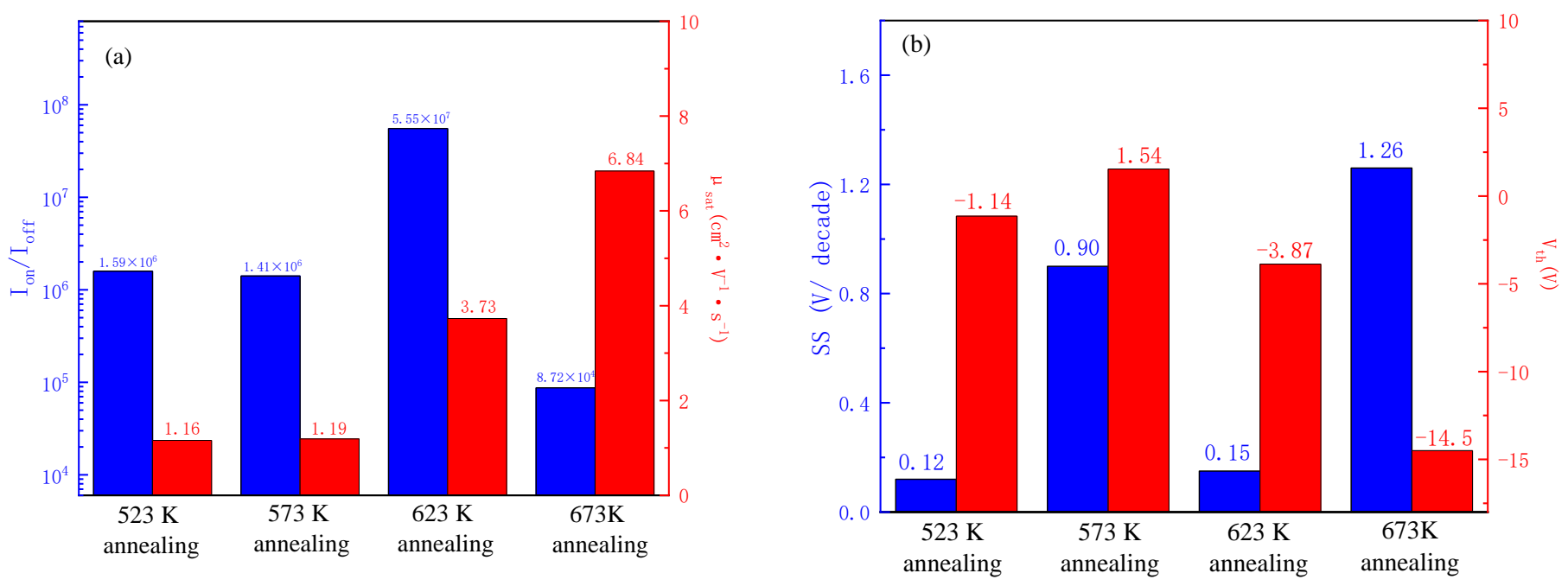

Figure 9. Main device performance of TFTs at different annealing temperatures: (a) $I_{o n} / I_{\text {off }}$ and $\mu_{\text {sat }}$, and (b) SS and $V_{\text {th }}$.

The leakage current of the TFT at the $623 \mathrm{~K}$ annealing is suppressed, which leads to the low off-state current. When the annealing temperature continues to increase, the carrier concentration increases; it causes the rising of the off-state current, and the $\mathrm{I}_{\mathrm{on}} / \mathrm{I}_{\text {off }}$ ratio drops significantly. The $\mathrm{I}_{\mathrm{on}} / \mathrm{I}_{\mathrm{off}}$ ratio decreases to $8.72 \times 10^{4}$ when the temperature rises to $673 \mathrm{~K}$. Meanwhile, the SS also decreases at first and then increases with the rising of the annealing temperature; the SS becomes lower when the temperature increases from $573 \mathrm{~K}$ to $623 \mathrm{~K}$, which means that the gate control ability of the devices is becoming enhanced, but it becomes so large that the performance of the TFTs becomes worse when the annealing temperature rises to $673 \mathrm{~K}$. The factors that contribute to this situation include the density of the surface defects at the interface layer and the decrease of the insulation layer when the annealing temperature rises, and it enhances the ability of the gate voltage to control the channel current so that the SS improves [38,39]. However, when the temperature reaches a high level, the electron concentration also becomes high, and there will be more defects related to oxygen in the active layer, and their abilities to scatter and trap electrons become stronger, which raises the density of the surface defects instead, and thus the SS ultimately increases. Furthermore, the improvement in the carrier mobility of the TFTs suggests that the performance of the devices becomes better in this respect. After the parameter optimization, the TFT devices with the ZATO films performed at the $623 \mathrm{~K}$ annealing with an $\mathrm{I}_{\mathrm{on}} / \mathrm{I}_{\mathrm{off}}$ ratio of $5.55 \times 10^{7}$, an SS value of $0.15 \mathrm{~V} /$ decade and a saturation mobility $\left(\mu_{\mathrm{sat}}\right)$ of $3.73 \mathrm{~cm}^{2} \cdot \mathrm{V}^{-1} \cdot \mathrm{s}^{-1}$. On the basis of the results, the ZATO TFTs show better properties compared to the ZTO TFTs of $2 \times 10^{6}, 0.45 \mathrm{~V} /$ decade and $1.47 \mathrm{~cm}^{2} \cdot \mathrm{V}^{-1} \cdot \mathrm{s}^{-1}$ by Lun et al. [40]. Besides, the $\mathrm{SnO}_{2}$ materials have hygroscopicity, which may reduce the stability of the TFT. An appropriate Al addition has the potential to improve its stability [17] and decrease the UV photoconductivity [41], which is conducive to the TFT applications in the display fields.

\subsection{Electrical Stability of ZATO TFT}

Figure 10a shows the transfer curves of the ZATO TFT at the $623 \mathrm{~K}$ annealing under the negative/positive bias stress (N/PBS) for $3600 \mathrm{~s}$. Figure $10 \mathrm{~b}$ shows the shifts of $\mathrm{V}_{\text {th }}$ $\left(\triangle V_{\text {th }}\right)$ in the ZATO TFT under the NBS/PBS. From Figure 10, it can be seen that the shifts of the $V_{\text {th }}$ value $\left(\triangle V_{\text {th }}\right)$ are $-8.01 \mathrm{~V}$ after the NBS was applied for $3600 \mathrm{~s}$, while $\triangle V_{\text {th }}$ is $2.66 \mathrm{~V}$ after the PBS was applied for $3600 \mathrm{~s}$. 

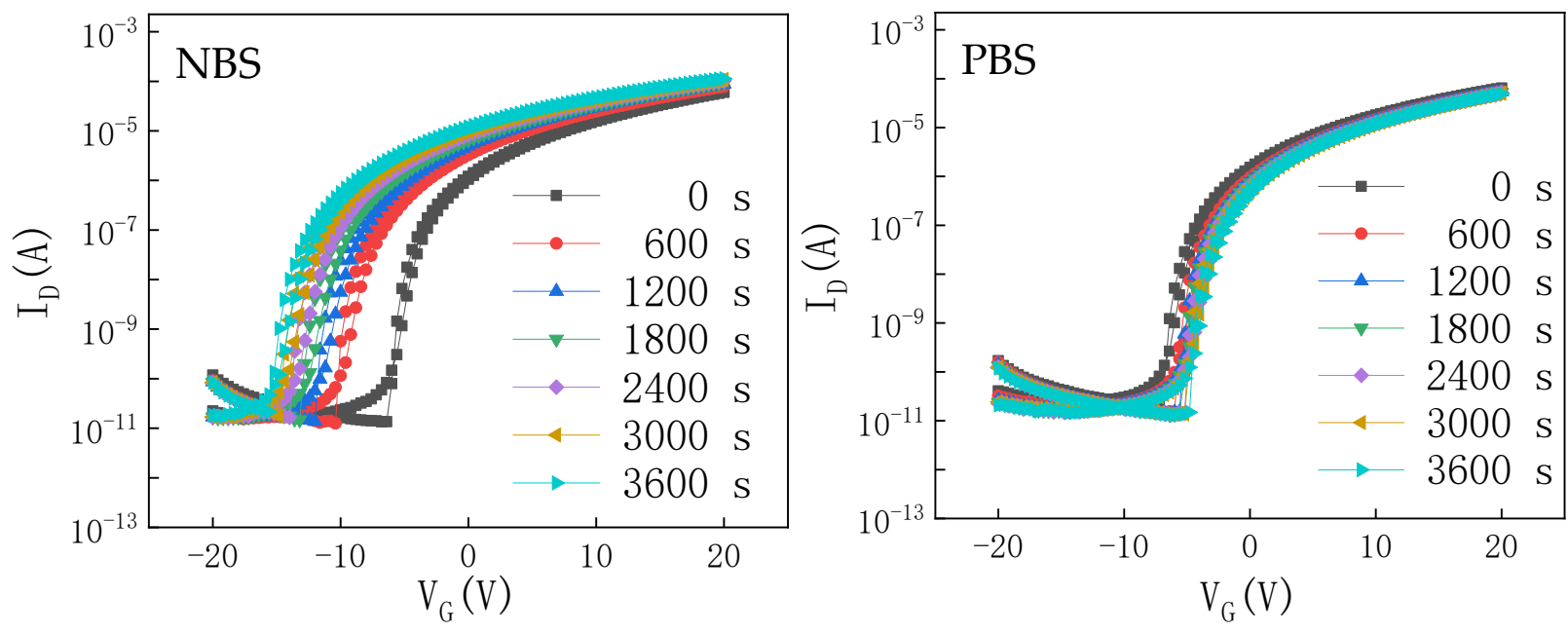

(a)

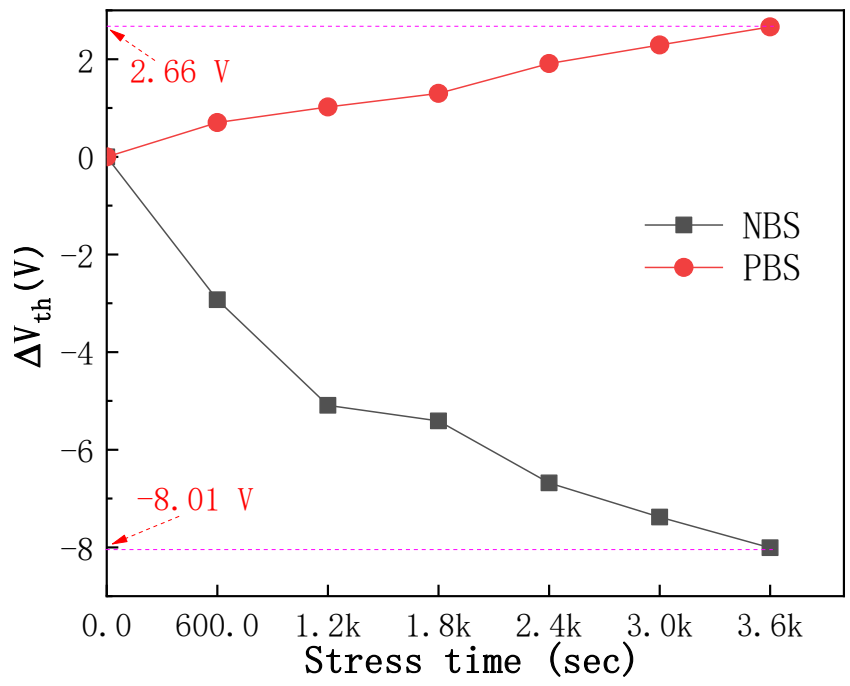

(b)

Figure 10. (a) Transfer curves of ZATO TFT annealed at $623 \mathrm{~K}$ under NBS $\left(\mathrm{V}_{\mathrm{G}}=-20 \mathrm{~V}\right)$ and PBS $\left(\mathrm{V}_{\mathrm{G}}=20 \mathrm{~V}\right)$, and $(\mathbf{b})$ the shifts of $V_{\text {th }}\left(\triangle V_{\text {th }}\right)$ under NBS/PBS.

\section{Conclusions}

In this paper, the $50 \mathrm{~nm}$ ZATO thin films were deposited on the glass substrate by $\mathrm{RF}$ magnetron sputtering with different gas pressures and oxygen/argon ratios, and the ZATO thin films are very smooth $\left(\mathrm{S}_{\mathrm{q}}<0.6 \mathrm{~nm}\right)$ and highly transparent $(90 \%$ in the visible region). Then, the ZATO thin films were used to fabricate the TFT devices successfully; the optimization parameter is $30 \mathrm{~nm}$-thick, the gas pressure is $3 \mathrm{mTorr}$, the oxygen/argon ratio content is $5 \%$ and the annealing temperature is $623 \mathrm{~K}$. The best comprehensive performance of the TFTs is as follows: the $\mu_{\text {sat }}$ is up to $3.73 \mathrm{~cm}^{2} \cdot \mathrm{V}^{-1} \cdot \mathrm{s}^{-1}$, the $\mathrm{I}_{\text {on }} / \mathrm{I}_{\text {off }}$ ratio reaches $5.55 \times 10^{7}$ and the SS value is $0.15 \mathrm{~V} /$ decade. The ZATO TFT at the $623 \mathrm{~K}$ annealing shifts $-8.01 \mathrm{~V}$ to the negative direction under the $-20 \mathrm{~V} \mathrm{NBS}$, while it shifts $2.66 \mathrm{~V}$ to the positive direction under the $20 \mathrm{~V}$ PBS. Based on the above, the TFT devices with the ZATO active layer have the advantages of being environmentally friendly and low-cost and have the potential for applications in next-generation displays.

Author Contributions: Funding acquisition, H.N. and R.Y.; investigation, M.Z.; project administration, K.L. and J.P.; resources, Z.X., H.N., X.Z. (Xiaochen Zhang), J.C., Z.Y., X.Z. (Xuan Zeng), R.Y. and J.P.; supervision, H.N.; validation, K.L.; visualization, M.Z.; writing-original draft, M.Z.; writing-review and editing, M.Z. and R.Y. All authors have read and agreed to the published version of the manuscript. 
Funding: This work was supported by the National Natural Science Foundation of China (Grant No. 22090024 and 62074059), Guangdong Major Project of Basic and Applied Basic Research (No. 2019B030302007), Guangdong Basic and Applied Basic Research Foundation (No. 2020B1515120020), Fundamental Research Funds for the Central Universities (No. 2020ZYGXZR060 and 2019MS012), Ji Hua Laboratory Scientific Research Project (X190221TF191), Sail Plan Special Innovative Entrepreneurial Teams in Guangdong Province (2015YT02C093), National College Students' Innovation and Entrepreneurship Training Program (No. 202010561001, 202010561004 and 202010561009), South China University of Technology 100 Step Ladder Climbing Plan Research Project (No. j2tw202102000) and 2021 Guangdong University Student Science and Technology Innovation Special Fund ("Climbing Plan" Special Fund) (No. pdjh2021b0036).

Conflicts of Interest: The authors declare no conflict of interest.

\section{References}

1. Tsai, J.; Wang, C.; Lin, M.; Huang, S. Analysis of Key Factors for Supplier Selection in Taiwan's Thin-Film Transistor Liquid-Crystal Displays Industry. Mathematics 2021, 9, 396. [CrossRef]

2. Feng, M.S.; Luo, T.C.; Liang, C.W.; Lee, C.D.; Tai, Y.H.; Cheng, H.C. Effects of $\mathrm{Al}_{2} \mathrm{O}_{3} / \mathrm{SiN}_{\mathrm{x}}$ Double-Layered Gate Dielectric on the Electrical characteristics of a-Si:H TFT. ITE Tech. Rep. 2017, 18, 57-66.

3. Guo, J.; Yu, Z.; Yan, W.; Shi, D.; Xue, J.; Xue, W. Two-stage degradation in n-channel LTPS-TFTs under negative and positive bias stresses. J. Soc. Inf. Disp. 2020, 28, 767-773. [CrossRef]

4. Oana, Y.; Kotake, H.; Mukai, N.; Ide, K. Electrical Properties of Polycrystalline Silicon MOSFETs on Glass. Jpn. J. Appl. Phys. 2014, 22, 493-496. [CrossRef]

5. Song, C.; Li, Y.; Gao, C.; Zhang, H.; Chuai, Y.; Song, D. An OTFT based on titanium phthalocyanine dichloride: A new p-type organic semiconductor. Mater. Lett. 2020, 270, 127666. [CrossRef]

6. Solah, P.; Min-Kyu, S.; Taehoon, S.; Jang-Yeon, K. Effect of X-ray irradiation on a-IGZO and LTPS thin-film transistors for radiography applications. Appl. Surf. Sci. 2021, 550, 149237.

7. Woo, H.; Kim, T.; Hur, J.; Jeon, S. Determination of intrinsic mobility of a bilayer oxide thin-film transistor by pulsed I-V method. Nanotechnology 2017, 28, 175201. [CrossRef]

8. Pan, Z.; Tian, X.; Wu, S.; Yu, X.; Li, Z.; Deng, J.; Xiao, C.; Hu, G.; Wei, Z. Investigation of structural, optical and electronic properties in Al-Sn co-doped ZnO thin films. Appl. Surf. Sci. 2013, 265, 870-877. [CrossRef]

9. Mallick, A.; Basak, D. Comparative investigation on cation-cation (Al-Sn) and cation-anion (Al-F) co-doping in RF sputtered ZnO thin films: Mechanistic insight. Appl. Surf. Sci. 2017, 410, 540-546. [CrossRef]

10. Salim, K.; Medles, M.; Nakrela, A.; Miloua, R.; Bouzidi, A.; Desfeux, R. Enhancement of optical and electrical properties of spray pyrolysed $\mathrm{ZnO}$ thin films obtained from nitrate chemical by Al-Sn co-doping. Optik 2020, 210, 164504. [CrossRef]

11. Qiu, X.; Liu, X.; Jiang, S.; Jiang, G.; Zhang, Q. Growth mechanism for zinc coatings deposited by vacuum thermal evaporation. J. Iron Steel Res. Int. 2021, 1-7. [CrossRef]

12. Zhou, Y.; Xu, W.; Lv, S.; Yin, C.; Li, J.; Zhu, B.; Liu, Y.; He, C. GaN codoping and annealing on the optoelectronic properties of SnO thin films. J. Alloys Compd. 2018, 732, 555-560. [CrossRef]

13. Sun, L.; Yuan, G.; Gao, L.; Yang, J.; Chhowalla, M.; Gharahcheshmeh, M.H.; Liu, Z. Chemical vapour deposition. Nat. Rev. Methods Primers 2021, 1, 5. [CrossRef]

14. Ma, H.; Hwang, J.B.; Chae, W.S.; Chung, H.S.; Choi, S.H.; Mahadik, M.A.; Jang, J.S. Magnetron sputtering strategy for Zr-Fe ${ }_{2} \mathrm{O}_{3}$ nanorod photoanode fabricated from $\mathrm{ZrO}_{x} / \beta-\mathrm{FeOOH}$ nanorods for photoelectrochemical water splitting. Appl. Surf. Sci. 2021, 549, 149233. [CrossRef]

15. Li, N.; Fu, Y.; Lu, Q.; Xiao, C. Microstructure and Performance of a Porous Polymer Membrane with a Copper Nano-Layer Using Vapor-Induced Phase Separation Combined with Magnetron Sputtering. Polymers 2017, 9, 524. [CrossRef]

16. Abegunde, O.O.; Esther, A.; Oladijo, O.P.; Majumdar, J.D. Surface Integrity of TiC Thin Film Produced by RF Magnetron Sputtering. Procedia Manuf. 2019, 35, 950-955. [CrossRef]

17. Jiang, Q.; Feng, L.; Wu, C.; Sun, R.; Li, X.; Lu, B.; Ye, Z.; Lu, J. Amorphous ZnAlSnO thin-film transistors by a combustion solution process for future displays. Appl. Phys. Lett. 2015, 106, 053503-1-053503-5. [CrossRef]

18. Kamali, M.; Khalaj, M.; Costa, M.E.V.; Capela, I.; Aminabhavi, T.M. Optimization of kraft black liquor treatment using ultrasonically synthesized mesoporous tenorite nanomaterials assisted by Taguchi design. Chem. Eng. J. 2020, 401, 956-958. [CrossRef]

19. Lin, Z.; Lan, L.; Peng, X.; Sheng, S.; Li, Y.; Wei, S.; Gao, P.; Lei, W.; Ning, H.; Peng, J. High-mobility thin film transistors with neodymium-substituted indium oxide active layer. Appl. Phys. Lett. 2015, 68, 488. [CrossRef]

20. Lu, K.; Yao, R.; Wang, Y.; Ning, H.; Guo, D.; Liu, X.; Tao, R.; Xu, M.; Wang, L.; Peng, J. Effects of praseodymium doping on the electrical properties and aging effect of InZnO thin-film transistor. J. Mater. Sci. 2019, 54, 14778-14786. [CrossRef]

21. Zhang, Y.; Zhou, X.; Zhou, T.; Nie, Z.; Jiancheng, D.A.; Yang, T. Influence of annealing treatment on properties of Ga-doped ZnO thin films deposited by RF magnetron sputtering. Electron. Compon. Mater. 2015, 12, 77-79, 83. 
22. Liu, J.; Zhang, G.; Guo, K.; Guo, D.; Shi, M.; Ning, H.; Qiu, T.; Chen, J.; Fu, X.; Yao, R.; et al. Effect of the Ammonium Tungsten Precursor Solution with the Modification of Glycerol on Wide Band Gap WO3 Thin Film and Its Electrochromic Properties. Micromachines 2020, 11, 311. [CrossRef] [PubMed]

23. Kong, P.; Pu, Y.; Ma, P.; Zhu, J. Relationship between Oxygen Defects and Properties of Scandium Oxide Films Prepared by Ion-Beam Sputtering. Coatings 2019, 9, 517. [CrossRef]

24. Yu, Y.; Zhang, X.; Zhou, Z.; Zhang, Z.; Bao, Y.; Xu, H.; Lin, L.; Zhang, Y.; Wang, X. Microscopic pump-probe optical technique to characterize the defect of monolayer transition metal dichal-cogenides. Photonics Res. 2019, 7, 712-721. [CrossRef]

25. Cheng, X.W.; Guan, Q.-F.; Fan, X.-H.; Chen, B. Effect of vacancy defect clusters on the optical property of the aluminium filter used for the space solar tel-escope. Chin. Phys. B 2010, 19, 417-421.

26. Ratana, T.; Amornpitoksuk, P.; Ratana, T.; Suwanboon, S. The wide band gap of highly oriented nanocrystalline Al doped ZnO thin films from sol-gel dip coating. J. Alloys Compd. 2009, 470, 408-412. [CrossRef]

27. Lu, J.G.; Fujita, S.; Kawaharamura, T.; Nishinaka, H.; Kamada, Y.; Ohshima, T. Carrier concentration induced band-gap shift in Al-doped Zn1-xMgxO thin films. Appl. Phys. Lett. 2006, 89, 262107-262107-3. [CrossRef]

28. Burstein, E. Anomalous Optical Absorption Limit in InSb. Phys. Rev. 1954, 93, 632. [CrossRef]

29. Zhang, X.; Liu, X.; Lu, K.; Ning, H.; Peng, J. The Performance of Zr-Doped Al-Zn-Sn-O Thin Film Transistor Prepared by Co-Sputtering. Appl. Sci. 2019, 9, 5150. [CrossRef]

30. Wei, J.; Fang, Z.; Peng, J.; Wei, C.; Zhu, Z.; Yao, R.; Zhou, S.; Yuan, W.; Lu, K.; Ning, H. High-performance spin-coated aluminum oxide dielectric fabricated by a simple oxygen plasma-treatment process. J. Phys. D Appl. Phys. 2018, 51, 01-08. [CrossRef]

31. Liu, X.; Cai, W.; Chen, J.; Fang, Z.; Ning, H.; Hu, S.; Tao, R.; Zeng, Y.; Zheng, Z.; Yao, R.; et al. A novel nondestructive testing method for amorphous Si-Sn-O films. J. Phys. D Appl. Phys. 2016, 49, 505102. [CrossRef]

32. Yasuno, S.; Kita, T.; Morita, S.; Hino, A.; Hayashi, K.; Kugimiya, T.; Sumie, S. Application of Microwave Photoconductivity Decay Method to Characterization of Amorphous In-Ga-Zn-O Films. IECIE Trans. Electron. 2012, E95.C, 1724-1729. [CrossRef]

33. Yao, R.; Zheng, Z.; Xiong, M.; Zhang, X.; Li, X.; Ning, H.; Fang, Z.; Xie, W.; Lu, X.; Peng, J. Low-temperature fabrication of sputtered high-k $\mathrm{HfO}_{2}$ gate dielectric for flexible a-IGZO thin film transistors. Appl. Phys. Lett. 2018, 112, 103501-103503. [CrossRef]

34. Yasuno, S.; Kita, T.; Morita, S.; Kugimiya, T.; Hayashi, K.; Sumie, S. Transient photoconductivity responses in amorphous In-Ga-Zn-O films. J. Appl. Phys. 2012, 112, 053715. [CrossRef]

35. Ye, Q.; Zhang, X.; Guo, D.; Xu, W.; Peng, J. Preparation of Highly Transparent (at 450-800 nm) SnO2 Homojunction by Solution Method and Its Photoresponse. Coatings 2020, 10, 399. [CrossRef]

36. Zhang, J.X.; Wang, Y.Q.; Lu, K.; Zhang, W.Y.; Li, J.P. TFT character of Al electrode in TFT-LCD. Chin. J. Liquid Cryst. Disp. 2017, $32,433-437$.

37. Herbei, E.E.; Jank, M.P.M.; Oertel, S.; Frangu, L.; Mușat, V. The Influence of Electrodes Deposition on the Interface and Dielectric Characteristics of Polymer Gate for Thin Films Transistors. Adv. Mater. Res. 2017, 4418, 227-232. [CrossRef]

38. Liu, Y.R.; Ren, L.F.; Yang, R.H.; Han, J.; Yao, R.H.; Wen, Z.C.; Xu, H.H.; Xu, J.X. Effects of Annealing Temperature on Electrical Properties of ZnO Thin-Film Transistors. J. South China Univ. Technol. 2011, 39, 103-107.

39. Jie, W.; Junfei, S.; Chengyuan, D.; Zhongfei, Z.; Yuting, C.; Daxiang, Z.; Zhe, H.; Runze, Z. Effect of active layer deposition temperature on the performance of sputtered amorphous In-Ga-Zn-O thin film transistors. J. Semicond. 2014, 35, 14003.

40. Huang, W.L.; Yang, C.C.; Chang, S.P.; Chang, S.J. Photoresponses of Zinc Tin Oxide Thin-Film Transistor. J. Nanosci. Nanotechnol. 2020, 20, 1704-1708. [CrossRef] [PubMed]

41. Jiang, Q.J.; Wu, C.J.; Feng, L.S.; Yu, G.Y.; Gong, L.; Ye, Z.Z.; Lu, J.G. Ultraviolet photoconductivity of amorphous ZnAlSnO thin-film transistors. RSC Adv. 2015, 5, 56116-56120. [CrossRef] 